\title{
Parental Care, Children's Cognitive Abilities and Economic Growth: The Role of Fathers
}

\author{
Debora Di Gioacchino \\ Department of Economics and Law, Sapienza University, Rome, Italy \\ Email: debora.digioacchino@uniroma1.it
}

Received January 20, 2012; revised February 25, 2012; accepted March 27, 2012

\begin{abstract}
Human capital is a key determinant of economic growth. Parents' involvement during childhood is a predictor of educational attainment later in life. Thus, time devoted by parents to childcare is an important productive activity for society. This paper presents a model in which parental childcare is a key factor in determining children's cognitive abilities. Parents' must allocate their time between paid job and childcare. Because of diminishing return, the optimal allocation of parents' time requires both parents to spend some time in childcare. Since a suboptimal allocation of time has implications both for children's cognitive abilities and for economic growth, our result has important policy implications.
\end{abstract}

Keywords: Childcare; Human Capital; Economic Growth

\section{Introduction}

Extensive research, mainly in psychology, has shown that children's early achievements are strong predictors of a variety of outcomes later in life, including educational attainment and, more generally, the accumulation of human capital [1]. Economists, on the other hand, have recognised the accumulation of human capital as a key determinant of economic growth. The issue of what determines ability of individuals at early stages of life is therefore critical for the design of public policy. The effect of parental time inputs on children's development has been widely analyzed, especially in the psychology and sociology literature. Empirical evidence on the impact of maternal employment on children's cognitive abilities is mixed but tend to find a negative association $([2,3]$ and literature cited therein). Cowley and Lieu [4] suggest that the cause of this negative association is to be found in the reduced time devoted to childcare by working mothers. However, very little has been said on the role of fathers. In fact, at least in two-parent households, reduced time devoted to child-care by working mothers could be offset by increased time investments by fathers; but little empirical evidence supporting this possibility has yet been provided. Although the involvement of fathers in childcare is rising over time, paternal labour supply seems to be unrelated or negatively related to the hours fathers spend with children ([5,6]. Yet, Rhum [3] finds that "paternal and maternal employment may affect child cognitive development in similar ways, suggesting that investments by fathers are also important ${ }^{1}$. This indicates that time investments of mothers and fathers may have qualitatively similar effects and raises the possibility of substitution across parents.”

If parental time-investment on childcare is a key factor in determining children's outcomes and if the development of children cognitive abilities is a predictor of their accumulation of human capital later in life and if, as it is recognised in the growth literature, human capital is a key engine for growth, then the allocation of parents' time between paid work and childcare might have crucial implications for economic growth and development.

Since Becker's seminal contribution [10,11], family economics has investigated the determinants of the allocation of time within the family. Based on a comparative advantage argument, Becker argues that the optimal allocation of time among parents should feature a complete specialization of tasks. However, he also recognises that "if both [parents] are required to produce certain commodities [e.g. children's cognitive abilities], then complementarities reduce the sexual division of labour in the allocation of time".

Along this lines, in this paper we present a simple

${ }^{1}$ Flouri and Buchanan [7] provide evidence that paternal and maternal involvement during childhood independently predict future educational attainment. Sarkadi et al. [8] conduct a systematic review of empirical evidence on the effects of fathers' involvement on children's development outcomes and conclude that "there is evidence to indicate that father's engagement positively affects the social, behavioural, psychological and cognitive outcomes of children. For an in depth discussion on father's role in children's development see [9]. 
model to describe the effects of parents' allocation of time on children's cognitive abilities and discuss the implications for public policy. In our model, a family is composed of two parents and a child. Parents (cooperatively) decide the allocation of their time between paid work and childcare. In making their decision they take into account the effects of this choice on the child's cognitive development. Because of diminishing return to childcare, the optimal allocation of time requires both parents to spend some time with their child. Limiting childcare to one parent reduces welfare even if it might increase consumption. Moreover, in a dynamical perspective in which children's cognitive abilities generate future innovation thus increasing the economy's productivity, not having both parents care for their children is a myopic solution.

\section{The Model}

Consider a family with two parents and a child. Parents must decide, cooperatively, the allocation of their time between market labour $(l)$ and childcare $(n)^{2}$. Formally, parent $i$ 's time constraint is

$$
l_{i}+n_{i}=1
$$

Parents' preferences are described by the utility function:

$$
W\left(c_{t}, a_{t+1}\right)=U\left(c_{t}\right)+\gamma V\left(a_{t+1}\right)
$$

where $\gamma$ is a measure of parents' altruism, $c_{t}$ is family's (current) consumption and $a_{t+1}$ is child's (future) cognitive abilities, which affect his human capital when adult, which in turn determines his future income and consumption. To simplify notation, in what follows, we omit the indication of time.

Family consumption is given by the budget constraint:

$$
c=(1-\tau)\left(h_{1} l_{1}+h_{2} l_{2}\right)
$$

where $\tau \in(0,1)$ is the labour-income tax rate, $h_{i}$ is parent $i$ 's level of human capital, $h_{i} l_{i}$ is his/her labour supply in efficiency units and the wage is normalised to 1 . We assume that the child's cognitive abilities depend on time devoted by his parents to childcare. We also assume that the only way parents take care of the child is by spending time with him, thus abstracting from childcare expenditures (such as books, toys, etc.) ${ }^{3}$. Parental childcare includes activities such as reading to or with children, helping with children's homework and talking with children. The "productivity" of parental childcare depends not only on the time devoted by the parent to this

${ }^{2}$ For simplicity, we do not consider leisure, or other components of non-paid work such as housework.

${ }^{3}$ These assumptions are not meant to deny the potential impact of non-parental care and income on children's development; they are made to focus on the role of parental time-input and in particular on the sharing of childcare between parents. activity $\left(n_{i}\right)$, but also on the parent's human capital $\left(h_{i}\right)$. The idea is that time devoted to childcare is more effective the higher is the parent's human capital; this means that an hour devoted to childcare by a more educated parent increases the child's cognitive abilities more than an hour spent in childcare by a less educated parent. We also allow for heterogeneity between parents. This is meant to capture the idea that mothers and fathers might influence different outcomes in children, at different development stages. In what follows, we consider a CES specification $^{4}$ :

$$
a=\left[\left(n_{1}^{\alpha_{1}} h_{1}^{\beta_{1}}\right)^{\rho}+\left(n_{2}^{\alpha_{2}} h_{2}^{\beta_{2}}\right)^{\rho}\right]^{\frac{1}{\rho}}
$$

where $\frac{1}{1-\rho}$ with $\rho \leq 1$ measures the elasticity of substitution between parents' childcare, $\alpha_{i}$ measures the "productivity" of parent $i$ 's time in increasing the child's cognitive abilities and $\beta_{i}$ measures how effective is parent $i$ 's human capital in increasing the child's cognitive abilities. We assume that time devoted to childcare is subject to decreasing marginal productivity, i.e.

$\alpha_{i} \in(0,1)^{5}$, but allow for the possibility of increasing return to education, i.e. $\beta_{i}$ may be greater than one.

To find the parents' optimal allocation of time, we must solve the following:

$$
\begin{aligned}
& \max W(c, a) \\
& c=(1-\tau)\left(h_{1} l_{1}+h_{2} l_{2}\right) \\
& a=\left[\left(n_{1}^{\alpha_{1}} h_{1}^{\beta_{1}}\right)^{\rho}+\left(n_{2}^{\alpha_{2}} h_{2}^{\beta_{2}}\right)^{\rho}\right]^{\frac{1}{\rho}} \\
& n_{1}+l_{1}=1 \\
& n_{2}+l_{2}=1
\end{aligned}
$$

After some manipulation, the first order conditions can

\footnotetext{
$\overline{{ }^{4} \mathrm{~A} \text { more general specification would consider parental }(x) \text { as well as }}$ non-parental care $(z)$ and it would also include family income $(y)$. In this case, a CES specification would be:

$$
a(x, z, y)=\left\{\mu\left[\lambda(x)^{\vartheta}+(1-\lambda) z^{\vartheta}\right]^{\frac{\varepsilon}{9}}+(1-\mu) y^{\varepsilon}\right\}^{\frac{1}{\varepsilon}}
$$

where $\frac{1}{1-\vartheta}$ is the elasticity of substitution between parental and non-parental childcare, $\frac{1}{1-\varepsilon}$ is the elasticity of substitution between care and income, $0 \leq \lambda \leq 1$ measures the relative importance of parental and non-parental care and $0 \leq \mu \leq 1$ the relative importance of care and income in the production of cognitive abilities. To focus on the effects of co-parenting on children's cognitive abilities, we have assumed that childcare is only provided by parents, that is $\lambda=1$ and that income does not affect children's cognitive abilities, that is $\mu=1$. Therefore, $a=x\left(n_{1}, n_{2}, h_{1}, h_{2}\right)$ Note however, that income affects children's well-being through family consumption.

${ }^{5}$ The idea is that long hours cause parents to be tired or stressed, reducing the quality of the time with children.
} 
be written as follows:

$$
\frac{n_{1}^{1-\rho \alpha_{1}} h_{1}^{1-\rho \beta_{1}}}{\alpha_{1}}=\frac{n_{2}^{1-\rho \alpha_{2}} h_{2}^{1-\rho \beta_{2}}}{\alpha_{2}}=\gamma \frac{a^{1-\rho}}{(1-\tau)} \frac{V_{a}}{U_{c}}
$$

Because of diminishing returns, in the optimal solution, both parents should supply some childcare and the time allocated to this activity should increase as parents' altruism increases. Ceteris paribus, the parent whose time is more "productive", i.e. the one with the greater $\alpha$ should spend more time caring for the child. The effect of a parent's education on the optimal supply of parental childcare depends on the value of $\beta$. If $\beta_{i}<1$, i.e. there are decreasing return to education in parental care, then more educated parents should spend less time in childcare and more working for a paid job; on the other hand, if $\beta$ is sufficiently greater than one $\left(\beta_{i}>\frac{1}{\rho}\right)$, i.e. the parent's education is sufficiently more productive in this activity than in the labour market, then more educated parents should offer more childcare. Notice also that a higher tax rate reduces consumption but, ceteris paribus, increases the time spent by parents in childcare and therefore the child's cognitive abilities ${ }^{6}$.

\section{An Example: Identical Parents}

Suppose that parents are identical, that is $\alpha_{i}=a$, $\beta_{i}=\beta$ and $h_{i}=h$. In this case, they should spend the same time in childcare: $n_{i}=n$. The total supply of parental time devoted to childcare would be $2 n$ and child's cognitive abilities would amount to $a=2 n^{\alpha} h^{\beta}$. $^{7}$ To obtain an analytical solution, consider a simple (quasi-linear) utility function, such as

$$
W(c, a)=c+\gamma \log a
$$

This implies

$$
\gamma \frac{V_{a}}{U_{c}}=\frac{\gamma}{a}
$$

In this case, the optimal allocation of time can be computed to be

$$
n=\frac{\alpha \gamma}{2 h(1-\tau)}
$$

and the corresponding child's cognitive abilities to be ${ }^{8}$

$$
a=2^{1-\alpha}\left(\frac{\alpha \gamma}{1-\tau}\right)^{\alpha} h^{\beta-\alpha}
$$

This simple example confirms that-in the optimal

\footnotetext{
${ }^{6}$ The effect of labour income taxation on growth, taking into account time spent by parents in childcare, has been emphasised by [12].

${ }^{7}$ Note that because of diminishing return to childcare $2 n$ units of parental time supplied by two parents "produce" higher child's cognitive abilities than the same amount of time supplied by a single parent.

${ }^{8}$ The related level of consumption would be $c=2 h(1-\tau)-\alpha \gamma$.
}

solution-time spent by each parent with the child (and the child's cognitive abilities) are positively affected by 1) parent's altruism $(\gamma)$; 2) the income tax rate $(\tau)$ and 3 ) the "productivity" of parents' time in childcare $(\alpha)$. More problematic is the upshot of parents' human capital. The higher is a parent's human capital, the more beneficial to the child is his/her time in childcare. On the other hand, the higher is a parent's human capital the more it is convenient for him/her to spend time in a paid job and the less in childcare. Thus, the result of an increase of parents' human capital on the child's cognitive abilities depends on a comparison of the elasticity of child's cognitive abilities with respect to parental time and human capital. If $\beta>\alpha$ then an increase in parent's human capital increases the child's cognitive abilities (via childcare). On the contrary, if $\beta<\alpha$ then the indirect effect, through reduced time in childcare, predominates and the child's cognitive abilities decrease ${ }^{9}$.

\section{Concluding Remarks}

Parental involvement during childhood supports the accumulation of human capital later in life; in turn, human capital accumulation promotes economic growth; therefore parental childcare is an important productive activity for society. This paper offers a model in support of the view that, because of diminishing returns and complementarities, childcare sharing between parents promotes children's educational attainment, and in the long run, economic growth ${ }^{10}$. Thus socially established norms on the division of labour within the family that limit fathers' participation in childcare result in an inefficient allocation of human resources. To the best of our knowledge, this paper is the first to emphasise the (negative) effects of gender inequality on human capital accumulation and growth via an inefficient allocation of "talents" in childcare $^{11}$. A main implication of our results is that "family friendly" policies are good not only for families but also for economic growth, the more so if one is also concerned with the quality of growth. Therefore, policies aiming at encouraging paternal childcare and promoting equal sharing of tasks within the family, including incentives for firms to use flexible-time contracts should be considered among pro-growth policies.

\section{REFERENCES}

[1] J. Currie and D. Thomas, "Early Test Scores, Socioeco-

${ }^{9}$ Computation of the derivatives of $n$ and $a$ w.r.t. the model's parameters is straightforward. An easy way is to transform into logarithms and then derive.

${ }^{10}$ Above and beyond increasing human capital and growth, a more equal distribution of tasks between parents might have positive effects on families' well-being.

${ }^{11}$ This relationship is analogous and dual to the causal link via an inefficient allocation of talents in the labour market (see [13] and literature cited therein). 
nomic Status, and Future Outcomes,” NBER Working Paper 6943, 1999.

[2] R. Bernal, "The Effect of Maternal Employment and Childcare on Children's Cognitive Development," International Economic Review, Vol. 49, No. 4, 2008, pp. 1173-1209. doi:10.1111/j.1468-2354.2008.00510.x

[3] C. Rhum, "Parental Employment and Child Cognitive Development,” Journal of Human Resources, Vol. 39, No. 10, 2004, pp. 155-192.

[4] J. Cowley and F. Lieu, "Mechanism for the Association between Maternal Employment and Child Cognitive Development,” NBER Working Paper 13609, 2007.

[5] S. Bianchi, "Maternal Employment and Time with Children: Dramatic Change or Surprising Continuity?” Demography, Vol. 37, No. 4, 2000, pp. 401-414. doi:10.1353/dem.2000.0001

[6] L. Fox, W. Han, C. Ruhm and J. Waldfogel, "Time for Children: Trends in the Employment Patterns of Parents, 1967-2009,” IZA DP No. 5761, 2011.

[7] E. Flouri and A. Buchanan, "Early Father's and Mother's Involvement and Child's Later Educational Outcomes," British Journal of Educational Psychology, Vol. 74, No. 2, 2004, pp. 141-53. doi:10.1348/000709904773839806
[8] A. Sarkadi, R. Kristiansson, F. Oberklaid and S. Bremberg, "Fathers' Involvement and Children's Developmental Outcomes: A Systematic Review of Longitudinal Studies,” Acta Paediatrica, Vol. 97, No. 2, 2007, pp. 153158. doi:10.1111/j.1651-2227.2007.00572.x

[9] M. Lamb, "How Do Fathers Influence Children's Development? Let Me Count the Ways,” In: M. Lamb, Ed., The Father's Role in Child Development, Wiley \& Sons, New York, 2010, pp. 1-26.

[10] G. Becker, "A Theory of the Allocation of Time," The Economic Journal, Vol. 75, No. 299, 1965, pp. 493-517. doi:10.2307/2228949

[11] G. Becker, “A Treatise on the Family,” Harvard University Press, Cambridge, 1991.

[12] A. Casarico and A. Sommacal, "Labor Income Taxation, Human Capital and Growth: The Role of Childcare," $C E$ SIFO Working Paper No. 2363, 2008.

[13] S. Klasen, "Low Schooling for Girls, Slower Growth for All? Cross-Country Evidence on Gender Inequality in Education on Economic Development," The World Bank Economic Review, Vol. 16, No. 3, 2002, pp. 345-373. doi:10.1093/wber/lhf004 